\title{
Is forced dextrality an explanation for the fall in the prevalence of sinistrality with age? A study in northern England
}

\author{
Simon J Ellis, P J Ellis, Eileen Marshall, Christine Windridge, Steven Jones
}

\begin{abstract}
Objectives-The fall in the prevalence of left handedness with age has been attributed to either premature mortality or a cohort effect of forced dextrality. Evidence for forced dextrality was sought to differentiate between these competing theories. Design-6097 Edinburgh handedness inventories were used to calculate laterality quotients (LQ) with and without the questions relating to writing and drawing. These questions might be expected to be most influenced by forced dextrality.

Setting-The study was performed in a small industrial town in Lancashire, UK. Participants-Using the British family practitioner service where over $95 \%$ of the population are registered with a general practitioner a response rate of $82.17 \%$ was obtained with respect to the Edinburgh Inventory.

Results-Questions about writing and drawing on the Edinburgh Inventory contributed to the positivity (right handedness) of the mean LQ, but equally across the ages. When a negative $L Q$ was used to define left handedness the prevalence of left handedness fell from $11.2 \%$ at age 15 to $4.4 \%$ at age 70 . Removal of the questions about writing and drawing caused the prevalence of left handedness to fall from $10.5 \%$ at age 15 to $4.95 \%$ at age 70 .

Conclusions-Less than $20 \%$ of the fall in the prevalence of left handedness was accounted for by questions relating to writing and drawing. The fall in the prevalence of sinistrals in older age groups is not adequately explained by cohort effects of forced dextrality on the writing hand.
\end{abstract}

(F Epidemiol Community Health 1998;52:41-44)

Practice, Horwich

Lancashire

P J Ellis

E Marshall

Leeds University

Computing Services,

Leeds

C Windridge

$\mathrm{S}$ Jones

Correspondence to: S J Ellis, Department of Neurology, Keele University, North Staffordshire Royal Infirmary, ST4 7LN.

Accepted for publication 24 April 1997 explain the fall in the prevalence of left handedness with age in cross sectional studies. These are:-

(1) Forced used of the right hand in childhood because of pressures in the home and school have made many naturally left handed persons right handed in previous generations, but with liberalisation of attitudes this effect is less pronounced so younger subjects are more likely to be left handed.

(2) We live in a dextrally biased world in that most design (scissors, machinery, etc) is for right handed persons. Throughout their life a left handed person is subject to continual pressures to do things with the right hand and over the years this results in a shift in handedness to the right resulting in a fall in left handedness in older age groups.

(3) Left handedness is a marker for decreased fitness to survive and left handers die prematurely resulting in fewer left handers present in older age groups.

This last explanation of premature mortality has been expounded by Halpern and Coren..$^{1-3}$ If the fall in the prevalence of left handedness is because of a survival disadvantage then left handedness would have an effect on life expectancy similar in magnitude to male sex. Despite a suggestion that sinistrals may be more accident prone, ${ }^{4}$ accidental death is an insufficient explanation to account for the fall of left handedness with age. ${ }^{5}$ Any association of left handedness with various diseases might provide a possible explanation of the age related fall in the prevalence of sinistrality. Geschwind and Behan reported left handedness to be associated with immune disease and migraine, ${ }^{6}$ but their study had important methodological flaws, not the least being that the left handers and control groups were obtained from different countries. Some studies have found increased left handedness in systemic lupus erythematosus, ${ }^{7}$ atopy,${ }^{8}$ insulin dependent diabetes mellitus, ${ }^{9}$ and inflammatory bowel disease, ${ }^{9}$ and others have not. ${ }^{10-14}$

This study takes advantage of the British general practitioner service where more than $95 \%$ of the population are registered with a general practitioner $(\mathrm{GP})^{15}$ and his/her notes and hospital correspondence are held by their GP. This gave us the opportunity to investigate the fall in the prevalence of left handedness with age by a more careful analysis of responses to the Edinburgh Inventory. ${ }^{16}$ We had previously noted a fall in the prevalence of left handedness with age. ${ }^{17}$ The advent of greater computing power and the theoretical work of Annett ${ }^{18}$ lead us to rexamine our data looking for evidence of a cohort effect in the responses to the drawing and writing questions.

\section{Methods}

A total of 7739 patients between the ages of 15-70 years from a group practice in a small industrial town (Horwich) in Lancashire, England, were mailed an Edinburgh Inventory to assess handedness (fig 1). Of the questionnaires arriving at the correct address $82.17 \%$ were returned correctly completed. The mean (SD) age of respondents was 41.26 (15.8), with 
Table 1 Regression analysis of $L Q$ with age. $L Q_{10}$, all questions; $L Q_{8}$, without questions about writing and drawing

\begin{tabular}{lllllll}
\hline$L Q$ & Sex & $D F$ & $\begin{array}{l}\text { Correlation } \\
\text { coefficient }\end{array}$ & $p$ Value & $\begin{array}{l}\text { Regression } \\
\text { coefficient }\end{array}$ & Constant \\
\hline $\mathrm{LQ}_{10}$ & Both & 6035 & 0.1243 & $<0.0001$ & 0.37 & 58.5 \\
$\mathrm{LQ}_{10}$ & Female & 3238 & 0.1312 & $<0.0001$ & 0.38 & 60.0 \\
$\mathrm{LQ}_{10}$ & Male & 2796 & 0.1160 & $<0.0001$ & 0.35 & 57.0 \\
$\mathrm{LQ}_{8}$ & Both & 6035 & 0.1275 & $<0.0001$ & 0.38 & 55.23 \\
$\mathrm{LQ}_{8}$ & Female & 3238 & 0.1355 & $<0.0001$ & 0.40 & 56.58 \\
$\mathrm{LQ}_{8}$ & Male & 2795 & 0.1178 & $<0.0001$ & 0.36 & 53.8 \\
\hline
\end{tabular}

Table 2 Regression analysis using +1 to denote right handed and -1 to denote left handed with age. $L \mathcal{E} R_{10}$, all questions; $L \mathcal{E} R_{8}$, without questions about writing and drawing

\begin{tabular}{lllllll}
\hline$L Q$ & Sex & $D F$ & $\begin{array}{l}\text { Correlation } \\
\text { coefficient }\end{array}$ & p Value & $\begin{array}{l}\text { Regression } \\
\text { coefficient }\end{array}$ & Constant \\
\hline${\mathrm{L} \& \mathrm{R}_{10}}$ & Both & 6022 & 0.0720 & $<0.0001$ & 0.0025 & 0.738 \\
$\mathrm{~L} \& \mathrm{R}_{10}$ & Female & 3232 & 0.0757 & $<0.0001$ & 0.0025 & 0.748 \\
$\mathrm{~L} \& \mathrm{R}_{10}$ & Male & 2788 & 0.0675 & $<0.001$ & 0.0024 & 0.727 \\
$\mathrm{~L} \& \mathrm{R}_{8}$ & Both & 6000 & 0.0589 & $<0.0001$ & 0.0020 & 0.761 \\
$\mathrm{~L}_{8}$ & Female & 3219 & 0.0706 & $<0.001$ & 0.0023 & 0.758 \\
$\mathrm{~L}_{8}$ & Male & 2779 & 0.0459 & $<0.05$ & 0.0016 & 0.764 \\
\hline
\end{tabular}

a mean age for men of 41.05 and for women of 41.44. Forty six per cent of the respondents were male. The laterality quotient (LQ) was calculated by the following formula, $\mathrm{LQ}=$ $(\mathrm{R}-\mathrm{L}) /(\mathrm{R}+\mathrm{L}) \times 100$, where $\mathrm{R}=$ total number of $+s$ in the right hand column and $L=$ the total number of $+s$ in the left hand column. ${ }^{16}$ The data from the Edinburgh inventories were reanalysed. The association with age, which had been reported previously from this population, ${ }^{17}$ was confirmed with age on this occasion as a continuous variable rather than using blocks of age groups. Secondly, the ques-
KEY POINTS

- Left handedness is rare in old age.

- Premature mortality and forced dextrality have been suggest as causes.

- Forced dextrality does not seem an adequate explanation.

tions on hand writing and drawing (questions 1 and 2) were omitted from the analysis and the association between age and LQ was again sought. By doing this the effect of forced dextrality should be taken out of the LQ as the other questions in the inventory are likely to be much less influenced by prejudices within the educational system.

\section{Results}

The 6097 Edinburgh inventories from our general population ${ }^{17}$ were reanalysed. Annett has cogently argued that influences on the writing hand are no longer as active in the educational system. ${ }^{18}$ This factor could have caused an apparent fall in the prevalence of left handedness with age, as there should be fewer forced dextrals allowing the natural number of left handers to be ascertained. The difference between the LQ using the 10 questions and the LQ derived only from the eight, leaving out questions about drawing and writing, is an estimate of forced dextrality.

\begin{tabular}{|c|c|c|}
\hline Surname & \multicolumn{2}{|c|}{ Male/Female } \\
\hline Forenames & \multicolumn{2}{|c|}{ Date of Birth } \\
\hline Address & \multicolumn{2}{|l|}{ Age } \\
\hline & Left & Right \\
\hline \multicolumn{3}{|l|}{1 Writing } \\
\hline \multicolumn{3}{|l|}{2 Drawing } \\
\hline \multicolumn{3}{|l|}{3 Throwing } \\
\hline \multicolumn{3}{|l|}{4 Scissors } \\
\hline \multicolumn{3}{|l|}{5 Toothbrush } \\
\hline \multicolumn{3}{|l|}{6 Knife (without fork) } \\
\hline \multicolumn{3}{|l|}{7 Spoon } \\
\hline \multicolumn{3}{|l|}{8 Broom (upper hand) } \\
\hline \multicolumn{3}{|l|}{9 Striking match (match) } \\
\hline \multicolumn{3}{|l|}{10 Opening box (lid) } \\
\hline \multicolumn{3}{|c|}{$\begin{array}{l}\text { Please indicate your preference in the use of hands in the following activities by putting a } \\
+ \text { in the appropiate column. Where the preference is so strong that you would never try } \\
\text { to use the other hand unless absolutely forced to, put }++ \text {. If in any case you are really } \\
\text { indifferent put }+ \text { in both columns. } \\
\text { Some activities require both hands. In these cases the part of the task, or object, for which } \\
\text { hand preference is wanted is indicated in brackets. } \\
\text { Please try to answer all the questions, and only leave blank if you have no experience at all } \\
\text { of the object or task. }\end{array}$} \\
\hline
\end{tabular}

Figure 1 The Edinburgh Inventory. 


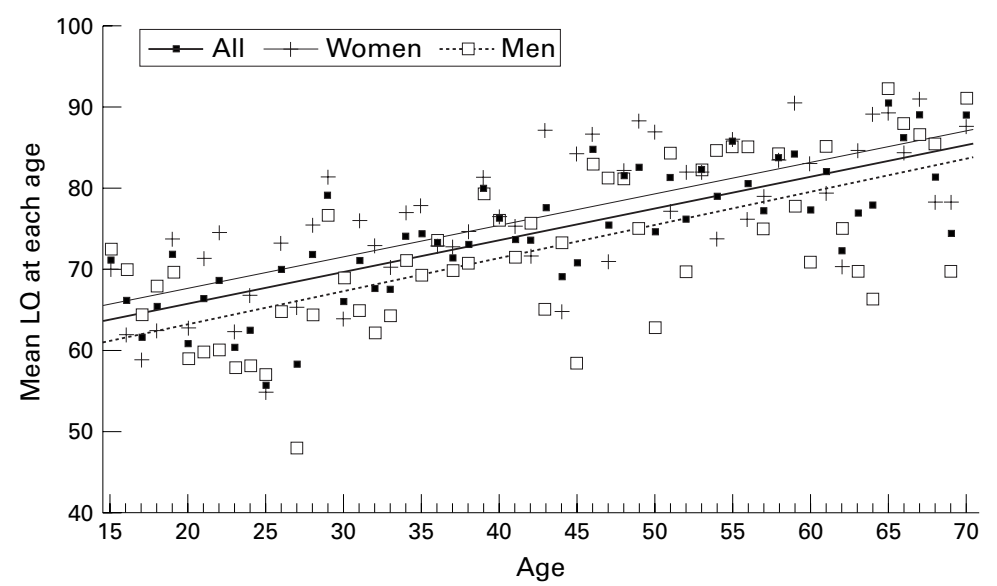

Figure 2 Change of mean LQ10 with age. All questions.

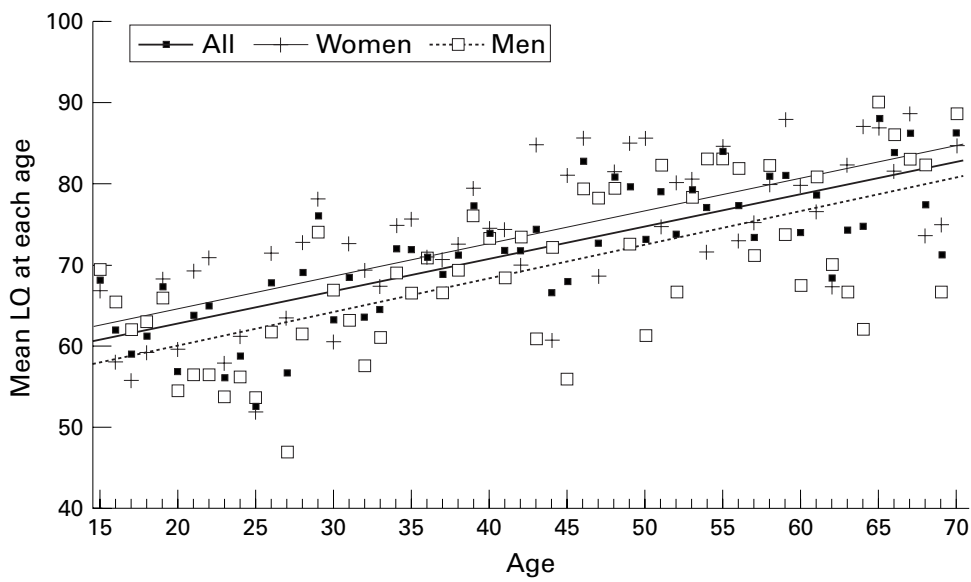

Figure 3 Change in mean LQ8 with age. Questions on writing and drawing excluded.

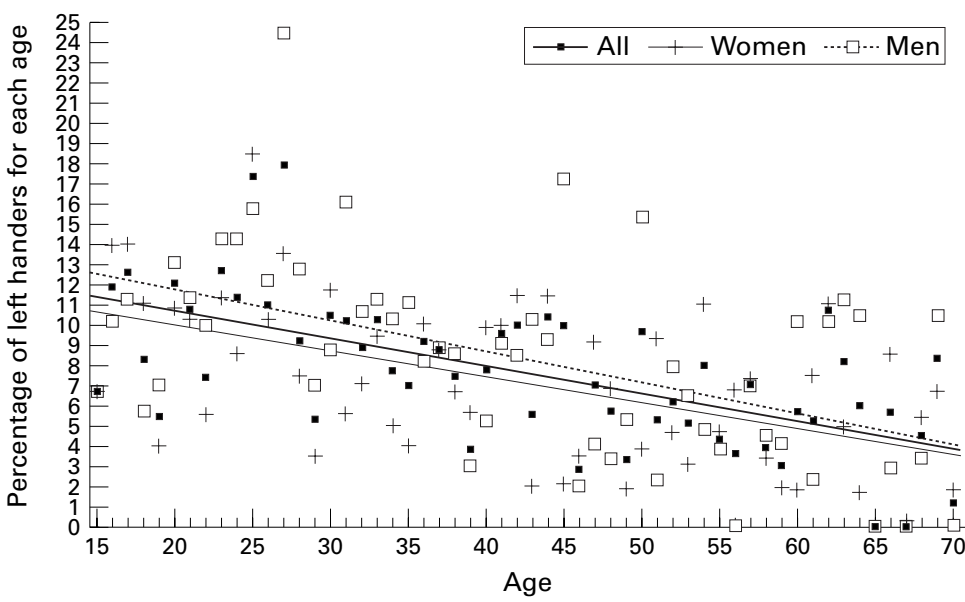

Figure 4 Left handedness with age. All questions.

REGRESSION ANALYSIS

A regression analysis was performed with age as the independent variable for the full inventory $\left(\mathrm{LQ}_{10}\right)$ and for the inventory with questions of writing and drawing omitted $\left(\mathrm{LQ}_{8}\right)$. This was performed for both sexes combined and separately.

As can be seen from the analysis (table 1), $L Q$ rises with age. Mean $L_{10}$ rises from 64.05 at age 15 to 84.4 at age 70 years. The omission of questions about writing and drawing in $\mathrm{LQ}_{8}$ produces a mean $\mathrm{LQ}_{8}$ rises from 60.97 at age
15 to 81.87 at age 70 years. The rise in LQ being 20.35 for $\mathrm{LQ}_{10}$ and 20.9 for $\mathrm{LQ}_{8}$. Once the contribution to right handedness effected by the inclusion of writing and drawing questions is taken into account, the omission of these questions does not produce a fall in the shift towards dextrality with age.

It could be argued that by using mean LQs you could have confounded magnitude with direction, so we reanalysed the data classifying subjects as either left or right handed on the basis of a negative or positive LQ respectively. Two different sets of left and right handers were identified. Those in whom the whole 10 question LQ had been used to derive the LQ before assigning handedness $\left(L \& R_{10}\right)$ and those in whom questions on writing and drawing had been omitted $\left(L \& R_{8}\right)$. Regression analyses were performed with age as the independent variable and right handedness $=+1$ and left handedness $=-1$. The constant therefore is the mean handedness where right handedness = +1 and left handedness $=-1$ at age 0 (table 2).

From these regression analyses we calculated the more conventional per cent of population who are left handed for any given age. Using the $L \& R_{10}$ definition the prevalence of left handedness fell from $11.2 \%$ at age 15 to $4.4 \%$ at age 70 . With writing and drawing excluded $\left(L \& R_{8}\right)$ the prevalence of left handedness fell from $10.5 \%$ at age 15 to $4.95 \%$ at age 70 . With writing and drawing included there is a fall in the prevalence of left handedness of $6.8 \%$. Without writing and drawing there is a fall in the prevalence of left handedness of $5.55 \%$. At best the addition of information about writing and drawing only accounts for $18 \%$ of the fall in left handedness. If forced dextrality in older generations is restricted to writing and drawing then less than $20 \%$ of the fall in the prevalence of left handedness is accounted for by this mechanism.

\section{GRAPHICAL REPRESENTATION}

The change in hand preference with age has been represented graphically in figures 2-5. For each year of age the mean LQ or percentage of left handers was calculated and a best fit trend line calculated. The graphical results closely mirror the regression analyses, however they are not strictly identical as age is a discontinuous variable, whereas in the analysis it is continuous.

As can be seen the addition or subtraction of questions that would have been most influenced by forced dextrality make comparatively little difference to the fall in the prevalence of sinistrality whether measured by mean LQ or by the proportion of left handers.

\section{Discussion}

It is not disputed that there is a reduced prevalence of left handedness in older age groups. The question being asked is whether this is because of premature mortality, forced dextrality or some other explanation. In a retrospective study of cricketers premature mortality for left handers was only observed for unnatural causes of death, particularly during warfare. ${ }^{19}$ However, this population of sportsmen would 


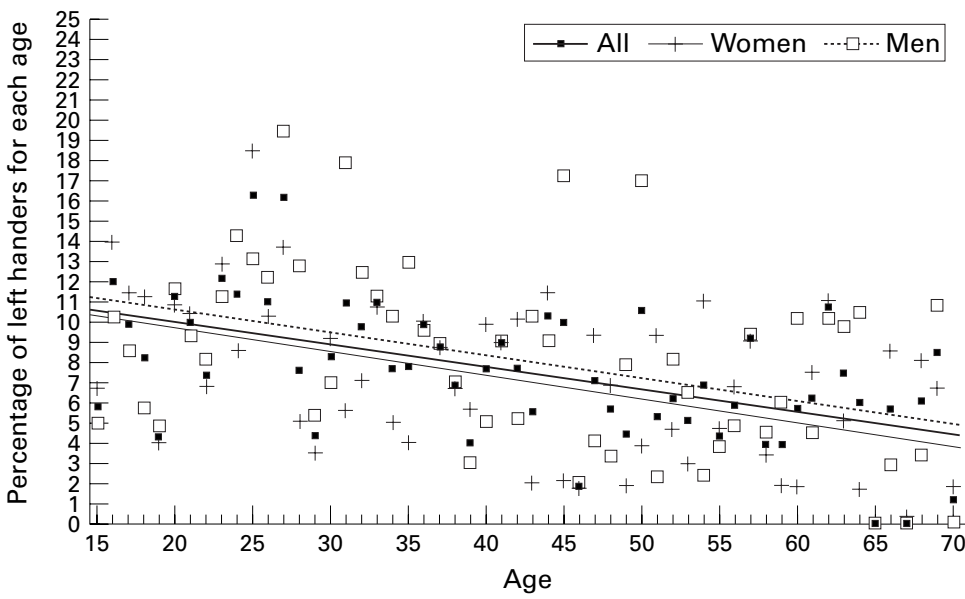

Figure 5 Left handedness with age. Questions on writing and drawing excluded.

be unlikely to contain persons who were poorly coordinated, or unfit and is therefore biased. If a proportion of left handers are so handed on a pathological basis ${ }^{20}$ one would not expect them to become cricketers, but they might be a source of premature mortality. Moreover half of the population (women) are not represented in such studies. If the fall in the apparent prevalence of left handedness with age was because of increasingly liberal attitudes to sinistrality in the classroom then one would expect less of a relation between age and LQ once writing and drawing had been removed from the analysis. This proved not to be the case. Most of the effect of age on the prevalence of right handedness is in an increased representation of the $\mathrm{LQ}+100$ in older age groups. To score +100 one has to mark all the boxes in the right hand column and none in the left hand column. In other words the subject has to be completely right handed for all 10 activities. A partial explanation for the rise in mean LQ with age would be that in older age groups there is an intolerance of deviation as part of the general attitudinal shifts seen in older age groups. This would lead to a shift in LQs to the positive as elements of sinistral "deviation" were suppressed.

The analysis of the results in terms of left or right handedness (negative or positive LQs respectively), removes the effects of shifts within a handedness group as an explanation for the fall in the prevalence of left handedness with age. When left handedness, as defined by a negative LQ, was used there was a small rise in left handedness when the writing and drawing questions were removed. This accounted for only $1.25 \%$ of the $6.8 \%$ fall in the prevalence of left handedness; less than $20 \%$ of the fall in left handedness can be explained by the forced dextrality hypothesis. The removal of writing and drawing questions did produce a rise in left handedness in older subjects as predicted by Annett. However the rise is too small to give support for the contention that educational liberalisation is the major reason for the fall in sinistrality seen in cross sectional studies. Porac, Coren, and Duncan criticised the cohort explanation as the fall in sinistrality with age has been observed since 1913 and any changes with the liberalisation of attitudes to sinistrals are too small to account for the whole observed effect. ${ }^{21}$ Using a different approach we have come to the same conclusion.

As with all population based studies the subjects who failed to respond are a potential source of bias, however with a high response rate $(82 \%)$ to the initial questionnaire this is less of a problem with this study than many other population based studies.

Explanations of the fall in left handedness in older age groups that rely on a cohort effect of liberalising attitudes to sinistrals are not supported by this study. Only careful prospective longitudinal studies can satisfactorily answer the important question of whether left handers suffer from premature mortality.

We wish to thank Marian Annett and Dorothy Bishop for their advice and encouragement. In addition we would like to thank advice and encouragement. In addition
Peter W Jones for statistical advice. Funding: this study was supported by the Medical Research
Council (G9222352N) and the Research Committee, North

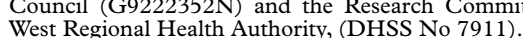

West Regional Health Auth

1 Halpern DF, Coren S. Do right-handers live longer? Nature 1988;333:213.

2 Coren S, Halpern DF. Left-handedness: a marker for decreased survival fitness. Psychol Bull 1991;109:90-106.

3 Halpern DF, Coren S. Handedness and life span. N Engl f Med 1991;324:998.

4 Coren S. Left-handedness and accident - related injury risk. Am F Public Health 1989;79:1040-1.

5 Ellis SJ. Longevity and left-handedness. Am F Public Health 1990;80:353.

6 Geschwind N, Behan P. Left-handedness: association with mmune disease, migraine, and developmental learning disorder. Proc Natl Acad Sci USA 1982;79:5097-100.

7 Lahita RG. Systemic lupus erythematosus: learning disability in the male offspring of female patients and relationship to laterality. Psychoneuroendocrinology 1988;13:385-96.

8 Smith J. Left-handedness: its association with allergic disease. Neuropsychologia 1987;25:665-74.

9 Searleman A, Fugagi AK. Suspected autoimmune disorders and left-handedness: evidence from individuals with diabeand left-handedness: evidence from individuals with diabetes, Crohn's disease

10 Salcedo JR, Spiegler JB, Gibson E, Magilary DB. The autoimmune disease systemic lupus erythematosus is not associated with left-handedness. Cortex 1985;21:645-7.

11 Schur PH. Handedness in systemic lupus erythematosus. Arthritis Rheum 1986;29:419-20.

12 Pennington BF, Smith SD, Kimberling WJ, Green PA, Haith MM. Left-handedness and immune disorders in familial dyslexics. Arch Neurol 1987;44:634-9.

13 Dellatolas G, Annesi I, Jallon P, Chavance M, Lellouch J. An epidemiological reconsideration of the GeschwindGalaburda theory of cerebral lateralisation. Arch Neurol 1990;47:778-82.

14 Bryden MP, McManus IC, Steenhuis RE. Handedness is not related to self-reported disease incidence. Cortex 1991; 27:605-11.

15 Fry J, Brooks D, McColl I. NHS data book. Lancaster: MTP Press Limited, 1984: 113.

16 Oldfield RC. The assessment and analysis of handedness: The Edinburgh Inventory. Neuropsychologia 1971;9:97111.

17 Ellis SJ, Ellis PJ, Marshall E. Hand preference in a normal population. Cortex 1988;24:157-63.

18 Annett $M$. The fallacy of the argument for reduced longevity in left handers. Percept Mot Skills 1993;76:295-8.

19 Aggleton JP, Bland JM, Kentridge RW, Neave NJ. Handedness and longevity: archival study of cricketers. BMF 1994; 309:1681-4

20 Satz P. Pathological left-handedness: An explanatory model. Cortex 1972;8:121-35.

21 Porac C, Coren S, Duncan P. Life-span age trends in laterality. F Gerontol 1980;35:715-21. hypothesis and a program for research. Arch Neurol 1985;42:521-52. 